Original Article

\title{
A QUALITATIVE STUDY OF PERSPECTIVES, EXPECTATIONS AND NEEDS OF EDUCATION IN CHRONIC OBSTRUCTIVE PULMONARY DISEASE (COPD)
}

\author{
RIFAATUL LAILA MAHMUDAH ${ }^{1 *}$, ZULLIES IKAWATI2, DJOKO WAHYONO ${ }^{2}$ \\ ${ }^{1 *}$ Doctoral Student of Pharmacy, Faculty of Pharmacy Gadjah Mada University, Sekip Utara Yogyakarta, 55281 Indonesia, ${ }^{2}$ Department of \\ Pharmacology and Clinical Pharmacy, Faculty of Pharmacy Gadjah Mada University, Sekip Utara Yogyakarta, 55281 Indonesia \\ Email: rifaatul@gmail.com
}

Received: 07 Oct 2016, Revised and Accepted: 10 Dec 2016

\begin{abstract}
Objective: Education of patients with Chronic Obstructive Pulmonary Disease is proven effective to improve the quality of life of patients. But more information is still required to find COPD patients needs in therapy. The authors set to explore perceptions, expectations, and needs of COPD patients as a part of pharmaceutical services.

Methods: This is a study of qualitative phenomenology analysis conducted in four hospitals in Mojokerto, East Java, Indonesia. The study interviews 14 patients diagnosed with COPD for at least three months and aged $\geq 40 \mathrm{y}$ old. Patients are interviewed about their perceptions, expectations, and needs about education experienced by them.

Results: All patients consider that education is important. Some of them think this education must be offered by a medical practitioner when they visit the hospital. This matter is less understood by the hospital. This matter results in the poor treatment of COPD patients and failure. Patients only receive education when they are diagnosed by a physician. Further education is not given if patients do not ask. Education material should cover
\end{abstract} causes of COPD, progression, and subsequent medication.

Conclusion: Education for COPD patients support treatment offered by medical practitioners. Education need room reserved for this purpose. Pharmacists also need to support this education by monitoring drug therapy and informs COPD patients about prescribed drugs.

Keywords: Perceptions, Expectations, Needs, and Chronic Obstructive Pulmonary Disease (COPD)

(C) 2016 The Authors. Published by Innovare Academic Sciences Pvt Ltd. This is an open access article under the CC BY license (http://creativecommons.org/licenses/by/4.0/] DOI: http://dx.doi.org/10.22159/ijcpr.2017v9i1.16601

\section{INTRODUCTION}

Chronic obstructive pulmonary disease (COPD) is one of the chronic diseases characterised by progressively worsening poor air flow related to abnormal inflammation response of lungs to dangerous particle or gas [1]. COPD is a chronic disease with many complications, but generally, it is curable and preventable. The most common complications of COPD have constrained activity, weight loss, increasing cardiovascular risk, osteoporosis [2], pneumonia [3], cor pulmonale, pneumothorax, pulmonary hypertension [4], and sometimes also depression [5]. COPD countermeasure also causes increasing direct cost to $\$ 18$ billion and indirect $\$ 14.1$ billion cost in Europe [2].

The effectiveness of COPD medications depends on several factors such as concordance, adherence, patient awareness, the involvement of healthcare professional, and family support [6]. Generally, confirmation of patients is low too long term medication especially COPD, less than $50 \%$, because of less optimal monitoring to prescribed drugs [7].

Conformity of COPD patients to medication may cause clinical outcomes and quality of life of patients [8]. The patient education program is an important strategy to support patients, effectively influences chronic disease medication [9]. The importance of health education on COPD patients related to the efficacy of health management and behaviour [10], on the other hand, COPD education is a novel thing compared to other educations of chronic disease like diabetes and asthma [11].

Healthcare professionals have a role in providing pharmaceutical service covering active and passive drug prescription via community and clinic, monitoring side effects of drugs, and cooperation among healthcare professionals to monitor patients' condition and development better. One research concludes that counselling intervention and traditional counselling are not effective in the long term $[12,13]$. Another method is required in combination to obtain continuous improvement from time to time. To make correct and proportional education plan, healthcare professionals, need to understand the opinion, expectation, and need of COPD patients [14]. Several prior qualitative researchers tried to uncover opinions of patients to arrange health education and service [15-20], so there is no gap between patients need and healthcare professionals. This research aims to explore perceptions, expectations, and needs of COPD patients as a part of pharmaceutical services

\section{MATERIALS AND METHODS}

This is a study of qualitative phenomenology analysis conducted in four hospitals in Mojokerto, East Java, Indonesia. Patients were interviewed about their perceptions, expectations, and wishes about patient education based on their experiences. The research employs interpretative phenomenological analysis (IPA) to explore opinions of COPD patients who become respondents about education related to COPD medication. Phenomenology comes from philosophical tradition, often employed as an approach to explore and understand people daily experiences. In semi-structural interviews, patients are given free questions to information related to their experiences.

Qualitative Interview is a method to collect data and information. Researchers give questions more freely without strict references to prearranged questions. This method aims to make two-way communications to avoid boredom, hence researchers are able to obtain more information. Qualitative interview method contains points of questions to be asked to interviewees, to me interview process easier. Letters of research approval are issued by four hospitals, i.e. (1) No. 028/RSIS-NU/Dir/2016; (2) No.445/ 1165/ 417.407/2016; (3) No. 423.4/575/416-211/2016; and (4) No. 070/226/418-206/2016.

\section{Population and sample}

Population is all patients suffering COPD treated in hospitals in Mojokerto. This research takes samples (research subject) from all 
COPD patients who met inclusion and exclusion criteria of research. Inclusions criteria are: (a) Adult COPD patient (40 y old or more) (1) and patient has been diagnosed for more than $3 \mathrm{mo}$; (b) stage IIIICOPD patient (1); and (c) patient is able to communicate. Exclusion criteria are COPD patients who need manual ventilation, suffer high comorbidity (kidney, liver, heart failures), have malignancy, or other condition causing patients unable to participate (such as dementia or delirium) [21].

Sampling technique in exploration stage uses purposive sampling, i.e. samples are adjusted with certain purposes. Samples in this stage must meet inclusion and exclusion criteria.

\section{Research tool and material}

Tools employed in this research are forms of patient approval and interview guidelines. Materials used in this research are medical records of patients in pulmonary clinics in hospitals in Mojokerto.

\section{RESULTS AND DISCUSSION}

The study interviews 14 patients diagnosed with COPD for at least three months, aged $40 \mathrm{y}$ old or more. Patients are interviewed about their perceptions, expectations, and wishes based on their experiences. Exploration finds that patients are mostly male, high school graduates, employees and housewives, have sufficient incomes, Javanese, and Muslims.

\section{Perception}

To the time, patients are given information by healthcare professionals, but most information only are given in initial diagnosis, further information are offered if patients ask themselves

Almost all patients say that information related to ongoing or future medications are provided, but they are only given in initial diagnosis by a physician and further information are not provided if patients ask. It is often that physician does not inform overall medication given to patients.

“... Oh, in the initial diagnosis, doctor said that the disease needed long time to cure, so I must visit regularly .... (Respondent F)"

Factors influencing patient awareness are internal and external [22]. Internal factors are:

1. Education. Education influences an individual, including his/her behaviour related to lifestyle. Generally, people with higher education are easier to understand information [22].

2. Occupation. Occupation is not a source of fun, but it is a way to make money that is boring, repeating, and full of challenges. Working consumes times. Working mothers influence overall family life [22]

3. Age. People regard older people more than those who are younger because of the consideration of experience and maturity [22].

External factors are:

1. Environment. According to An. Mariner, the environment is overall condition around people and its influence that affect development and behaviour of a person or group [22].

2. Socio-cultural. The socio-cultural system in the community is able to affect behaviour to accept information [22].

\section{Education received by patients so far is not sufficient}

Education for the patient in hospitals in Mojokerto only explains medication, so it is not enough for COPD patients. Education needs improvement, both from physicians and other healthcare professionals. Based on questions given to COPD patients, answers are almost identical when patients are asked about ongoing and future medication.

"... The chest is heavy, so this (holding MDI pointed to chest) is sprayed to chest (Respondent D)."

Education is important in long-term disease management of stable COPD [23]. Health education is important for COPD patients as it improves the efficacy of health management and behaviour. It is closely related to goals of health program [10]. Education is expected to make patients [23]: [1] know disease progression and medication, [2] receive the best medication, [3] able to do normal activities, and [4] have improved the quality of life.

A meta-analysis about pulmonary rehabilitation program on COPD patients finds lessening dyspnea and fatigue, improving emotion, and also better patient's control over his/her condition. According to Stoilkova, Janssen, and Wouters [2013] [24], education materials are:

1. Identification and first aid when relapse occurs.

2. Planned action by patients themselves when relapse occurs

3. Decision of end of life for COPD patient

4. Coping mechanism for COPD patient

5. Normal pulmonary physiology anatomy

6. COPD pathophysiology

7. Interpretation of medical examination

8. Respiration strategy

9. Role and rationalisation or medication, including oxygen therapy

10. Effective use of respiration tool

11. Method to clean secretion

12. Healthy food consumption

13. Avoiding irritants including how to stop smoking

14. Anxiety or panic control, including relaxation and stress management.

15. Benefits of physical exercises and activities

16. Energy conservation during daily activities

17. Communication with health care facility

18. Activities in spare times.

Family support may influence faith and health of a person, including medication program to give. The family also supports and makes a decision related to treatment received by family members. Emotional support from a family member, friend, time, and money also affect conformity to medication. For instance, lack of transportation or money affects patient conformity to medication. Healthy behaviour is affected by habits, so patients need to develop a strategy to change their habits and keep the change intact [25-26].

Support from healthcare professionals is another factor affecting conformity. This support is necessary as patients need to understand that the new healthy habits are very important. Healthcare professionals need to show enthusiasm to patients' effort continuously, especially for patients who able to adapt to their medication plans [25-26].

Patients think that health education related to COPD medication is important

Almost all patients say that health education related to COPD medication is important. But hospitals often do not understand that education is important for patient treatment. Several patients wishes such education is provided by a physician every time patient visit hospital. Based on COPD patients' answers, they have understand the important of education to support medication and treatment. Medication success depends on the suitable education program.

“... Like me. This is Indonesia; we are countrymen, but we need to know why we suffer, must the drug we need and remember it after some time, (Respondent $\mathrm{H})$."

Education is important for long-term COPD medication because COPD is a chronic disease that is irreversible and progressive. Therefore patients need to adjust to the limitation of activity ad decrease of pulmonary function, as it shows the success of COPD medication via education [1]. 


\section{Expectation}

\section{Education involves not only patient but also family}

Education is expected to involve both patient and family. Education begins since the patient is diagnosed with COPD and continues in every visit. Hospitals and Mojokerto should consider education for family members of the patient, as educated family members are able to motivate patient to follow medication and improve his/her quality of life. They also need to pay attention to feeling and anxiety of patient when education begins.

“... Every time I visit, later at home, my child always ask what doctor says and what doctor prescribe. My child does not go to medical school but always concerned to my condition (Respondent B)"

\section{Location to provide education must make patient comfortable}

Intensive education may be offered in a rehabilitation facility or counselling room because it needs special time and special tools. Education is expected to decrease patient anxiety and improve spirit to life even if the patient experiences limited activities. Patients say that they receive education in the examination room and some of them also in the waiting room. Patients feel anxious in their first time to receive an education because they know for the first time the illness they suffer, but along time patients feel more relaxed and optimistic to receive medication.

"Usually pharmacist only inform how to take this drug in the drugstore, how to use this drug by spraying .... (Respondent D).

\section{Needs}

\section{Education materials need improvement}

Patients say that the topic offered in education is related to basics of COPD, covering causes and medication. Materials given are insufficient. Generally, education needs to cover basics of COPD, drugs and their indications and side effects, prevention, worsening, how to stop smoking, and adjustment of activities. The emphasis of education Mojokerto Hospital, according to patients, is related to medication, only 2 persons (25\%) say that medical personal emphasise to stop smoking.

“... Nurses also say that patient must restraint from exhaustion and stop smoking (Respondent J and D)"

When patients are asked about education material given, almost all of them reply that they are informed about basics of COPD and medication to take. This education material is very insufficient.

"How to say it, I am sick, but the doctor knows more, all of them ... I don't know (Respondent A)"

Smoking is the primary cause of COPD. Smokers are $30 \%$ riskier to suffer COPD than non-smokers. It also causes $85-90 \%$ of COPD cases. COPD risk on smokers depends on how many cigarettes smoked, the age starts to smoke, how many cigarettes smoked per year, and duration to smoke [27]. The emphasis to avoid smoking on COPD patients is expected to decrease inhalation of particles and gases both whether as active or passive smokers. These particles and gases may worsen the condition of COPD patients.

\section{Education method needs adjustment}

Method to offer education needs to consider backgrounds of patients. Materials also need to meet the severity of disease, school education, socio-environment, culture, and economic condition of patients. When asked about language and media, all patients say that medical terms are used and only use leaflets.

“... Explanation use languages I don't familiar with, like the photo of thorax .... There sometimes leaflets are offered to read when we are waiting to receive our medication (Respondent C)"

Technology is able to help, so education is easier to be received by patients. According to Nguyen (2013] [28], internet based dyspnea education on COPD patients results in patient conformity to receive therapy after 12 mo. Novel technology and service to give education to COPD patients are telehealth [29].
The employed language should be a simple and easy to understand language, directly discuss the problem, and contains easy to understand not complex topics.

“We didn't go to medical school, usually working on farm or factory, if it is explained using everyday language, I can understand (Respondent I)"

Education must use simple language and easy to understand; it needs to discuss the problem directly on the spot. Education must repeatedly be offered without too many materials in every session [23], i.e.:

\section{Basics of COPD}

2. Drugs, indications and side effects

3. How to prevent worsening disease

4. Avoiding cause (stop smoking)

\section{Activity adjustment}

The media used must have various forms to increase patient's awareness. Distribution of cellular phones in Indonesia, especially among COPD patients, is considered by the researcher to be a tool to help educate and spread information among COPD patients.

"It is long to wait for a prescription, but in TV there is no program explaining disease formed like an advertisement (Respondent M)"

\section{Counselling room needs adjustment}

Education in hospitals in Mojokerto has not had a room reserved to counselling, or even tools to help education. Patients who unfamiliar with medical terms often feel confused. This unawareness may increase patients' anxiety, thus affecting their quality of life.

“... usually it is like this. Doctor examines and prescribes drugs ... at most only informed about the schedule of my next visit. It would be better if we are offered information or room to consult (Respondent A)."

\section{CONCLUSION}

Perception of respondents tells that there are information offered by medical personal, especially when they are diagnosed in the first time. Further information are only offered if patients ask. Education received by patients is considered insufficient. Patients consider education related to COPD medication is very important.

Respondents expect that education involves not only patients, but also family members of the patient to support patient mentally. The location to offer education also needs to make patients feel comfortable.

Respondents, as COPD patients, need more materials for education, better method, and counselling room reserved for this purpose.

Therefore, special media need to be developed for COPD patients, so COPD patients are able to receive fast, clear, and comprehensive information.

\section{CONFLICT OF INTERESTS}

\section{Declared none}

\section{REFERENCES}

1. Global Initiative for Chronic Obstructive Lung Disease. Global Strategy for The Diagnosis, Management, and Prevention of Chronic Obstructive Pulmonary Disease (Updated). UK; 2015.

2. Oemiati Ratih. Kajian epidemiologi penyakit paru obstuktif kronik (PPOK). Med Litbangkes 2013;23:82-8.

3. Calverley PM, Stockley RA, Seemungal TA, Hagan G, Willits LR, Riley JH, et al. investigating new standards for prophylaxis in reduction of exacerbations (inspire) investigators: reported pneumonia in patients with COPD: findings from the INSPIRE study. Chest 2011;139:505-12.

4. Adil Shujaat, Ruth Minkin, Edward Eden. Pulmonary hypertension and chronic corpulmonale in COPD. Int J Chronic Obstruct Pulm Dis 2007;2:273-82. 
5. Kurt B Stage, Thomas Middelboe, Tore B Stage, Claus H Sorensen. Depression in COPD-management and quality of life considerations. Int J Chronic Obstruct Pulm Dis 2006;1:315-20.

6. Mousing CA, Lomborg K. Self-care 3 mo after attending chronic obstructive pulmonary disease patient education: a qualitative descriptive analysis. Patient Prefer Adherence 2012;6:19-25.

7. Boven JFM Van. Medication monitoring and optimisation: a targeted pharmacist program for effective and cost-effective improvement of chronic therapy adherence. J Managed Care Specialty Pharm 2014;20:786-92.

8. Bourbeau J, SJ Bartlett. Patient adherence in COPD. Thorax 2008;63:831-8

9. Lorig KR, Holman H. Self-management education: history, definition, outcomes, and mechanisms. Ann Behav Med 2003; 26:1-7.

10. Harris M, Smith BJ, Veale A. Patient education programs can they improve outcomes in COPD? Int J Chron Obstruct Pulmon Dis 2008;3:109-12.

11. Monninkhof EM, Van der Valk PD, van der Palen J. Selfmanagement education for the chronic obstructive pulmonary disease. Cochrane Database of Syst Rev 2004; 4:CD002990.

12. Hailey BJ, Moss SB. Compliance behaviour in patients undergoing haemodialysis : a review of the literature. Psycho Health Med 2000;5:395-406.

13. Lii YC, Tsay SL, Wang TJ. Group intervention to improve the quality of life in haemodialysis patients. J Clin Nursing 2007; 16(11C):268-75.

14. World Health Organization Health. Education: theoretical concepts, effective strategies and core competencies: a foundation document to guide the capacity development of health educators; 2012.

15. Papp R, Borbas I, Dobos E, Bredehorst M, Jaruseviciene L Vehko $\mathrm{T}$, et al. Perceptions of quality in primary health care: perspectives of patients and professionals based on focus group discussions. BMC Fam Pract 2014;15:128.

16. Yiranbon E, Lulin Z, Antwi HA, Marfo EO, Amoako KO, Offin DK Exploring the expectation and perception of healthcare needs of the elderly in ghana: an empirical analysis. Int J Acad Res Economics Management Sci 2014;3:165-83.

17. Anderson RT, Barbara AM, Weisman C, Scholle SH, Binko J. A qualitative analysis of women's satisfaction with primary care from a panel of focus groups in the national centers of excellence in women's health. J Women's Health Gender-Based Med 2001;10:637-47.

18. Attree M. Patients and relatives experiences and perspectives of good and not so good quality of care. J Adv Nursing 2001;33:456-66.

19. Dawn AG, Lee PP. Patient expectations for medical and surgical care: a review of the literature and applications to ophthalmology. Survey Ophthalmol 2004;49:513-24

20. Ngo-Metzger Q, Massagli MP, Clarridge BR, Manocchia M, Davis RB. Linguistic and cultural barriers to care: perspectives of Chinese and Vietnamese immigrants. J General Internal Med 2003;18:44-52.

21. Dyk L Van, Campus P, Africa S. A review of telehealth service implementation frameworks. Int J Environ Res Public Health 2014;11:1279-98.

22. Wawan dan Dewi. Pengetahuan, sikap, dan Perilaku Manusia Yogyakarta: Nuha Medika; 2010.

23. Perhimpunan Dokter Paru Indonesia. Penyakit Paru Obstruktif Kronik (PPOK): Pedoman Diagnosis and Penatalaksanaan Di Indonesia; 2011.

24. Stoilkova A, Janssen DJA, Wouters EFM. Educational programmes in COPD management interventions: a systematic review. Res Med 2013;107:1637-50.

25. Rapoff MA, Bartlett SJ. Adherence in children and adults. In: Bartlett SJ. ed. Clinical care in the rheumatic diseases. Atlanta: Am College Rheumatol; 2006. p. 279-84.

26. World Health Organization. Adherence to long-term therapies Evidence for action. Geneva: World Health Organization; 2003.

27. Ikawati Z. Farmakologi Sistem Pernafasan. Pustaka Adipura, Yogyakarta; 2011

28. Nguyen HQ, Fan VS, Herting J, Lee J, Fu M, Chen Z, et al. Patients with COPD with higher levels of anxiety are more physically active. Chest 2013;144:145-51.

29. Dabrowska EK. Telehealth in the UK: a critical perspective. Electronic J Business Res Methods 2003;2:37-46.

\section{How to cite this article}

- $\quad$ Rifaatul Laila Mahmudah, Zullies Ikawati, Djoko Wahyono. A qualitative study of perspectives, expectations and needs of education in chronic obstructive pulmonary disease (COPD). Int J Curr Pharm Res 2017;9(1):32-35. 